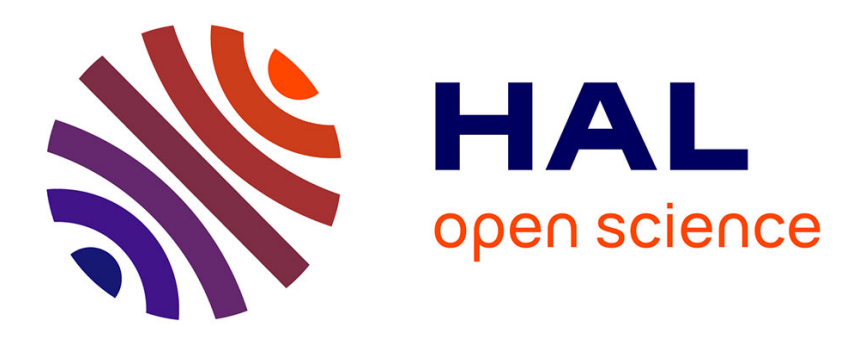

\title{
Volume anomaly in ferrimagnetism
}

H. Pascard, A. Globus

\section{- To cite this version:}

H. Pascard, A. Globus. Volume anomaly in ferrimagnetism. Journal de Physique Lettres, 1981, 42 (13), pp.319-322. 10.1051/jphyslet:019810042013031900 . jpa-00231936

\section{HAL Id: jpa-00231936 https://hal.science/jpa-00231936}

Submitted on 1 Jan 1981

HAL is a multi-disciplinary open access archive for the deposit and dissemination of scientific research documents, whether they are published or not. The documents may come from teaching and research institutions in France or abroad, or from public or private research centers.
L'archive ouverte pluridisciplinaire $\mathbf{H A L}$, est destinée au dépôt et à la diffusion de documents scientifiques de niveau recherche, publiés ou non, émanant des établissements d'enseignement et de recherche français ou étrangers, des laboratoires publics ou privés. 


\title{
Volume anomaly in ferrimagnetism $\left({ }^{*}\right)$
}

\author{
H. Pascard and A. Globus \\ Equipe de Recherche Matériaux Magnétiques, C.N.R.S., 92190 Meudon Bellevue, France
}

(Reçu le 13 février 1981, révisé le 30 avril, accepté le 6 mai 1981)

\begin{abstract}
Résumé. - L'anomalie de volume $\Delta V / V$ due à l'énergie magnétique associée aux interactions d'échange est déterminée expérimentalement pour $\mathrm{Y}_{3} \mathrm{Fe}_{5} \mathrm{O}_{12}$. Les valeurs mesurées de $77 \mathrm{~K}$ à $T_{\mathrm{c}}$ coïncident avec les valeurs obtenues à partir de l'expression basée sur l'approximation du champ moléculaire et sur les théories de Néel de l'anomalie de dilatation et du ferrimagnétisme. Ces résultats sont comparés à ceux obtenus par d'autres auteurs pour des matériaux ferromagnétique et antiferromagnétique à moments localisés : une courbe réduite est obtenue.
\end{abstract}

\begin{abstract}
The volume anomaly $\Delta V / V$ due to the magnetic energy corresponding to the exchange interactions is experimentally determined for YIG. The experimental values (from $77 \mathrm{~K}$ to $T_{\mathrm{c}}$ ) agree with the values deduced from the theoretical expression based on the Nél's theories of volume anomaly and of ferrimagnetism. These results are compared with those obtained by other authors on ferromagnetic and antiferromagnetic materials with localized magnetic moments : a reduced curve is obtained.
\end{abstract}

1. Introduction. - This letter reports some results of a systematic investigation in order to check experimentally a hypothesis proposed previously by one of the authors about the relation between the magnetoelastic anisotropy found in ferrimagnetic polycrystals, and the volume anomaly [1]. So, the results about the volume anomaly in ferrimagnetism are presented.

The volume anomaly of cubic magnetic materials corresponds to the isotropic spontaneous deformation accompanying the occurrence of the magneticorder state associated with exchange interactions at and below the critical temperature $T_{\mathrm{c}}$.

For ferromagnetic materials Neel showed that this volume anomaly was due to the variation of the interaction energy (coupling forces) between magnetic atoms as a function of the distance of the magnetic layers [2].

For insulating cubic magnetic materials Bloch stated precisely the law for the volume dependence of the superexchange interactions [3] and related quantitatively the volume anomaly at $0 \mathrm{~K}$ to the variation of $T_{c}$ with pressure [4].

2. Theoretical expression of the volume anomaly. Let us consider a magnetic material with localized

(*) La version française de cet article a été acceptée aux Comptes Rendus de l'Académie des Sciences et elle est insérée dans le $\mathbf{n}^{\circ}$ du 2 février 1981, série II, p. 439. moments and one kind of magnetic ion and assume that the exchange coupling is of the Heisenberg type $-2 J_{i j} \mathbf{S}_{i} \mathbf{S}_{j}$. In the approximation of the molecular field theory the magnetic energy per unit volume is written as [5] :

$$
E_{\mathrm{m}}=-N \frac{3}{2} k_{\mathrm{B}} T_{\mathrm{c}} \frac{S}{S+1} \sigma^{2},
$$

where

$N$ is the number of magnetic ions per unit volume, $T_{\mathrm{c}}$ the critical temperature (directly proportional to the exchange interactions),

$S$ the spin of the magnetic ion and

$\sigma$ the reduced magnetization $m(T) / m(0)$.

Assuming a volume dependence of the exchange interaction of the form $V^{\beta}$, for a small volume variation $\Delta V / V, T_{\mathrm{c}}$ can be written as [6] :

$$
T_{\mathrm{c}}=T_{0}\left(1+\beta \frac{\Delta V}{V}\right)
$$

$T_{0}$ would be the critical temperature if the lattice were not compressible, $\beta$ may be positive or negative.

The sum of the magnetic and elastic energies per unit volume is :

$$
\begin{aligned}
E=-N \frac{3}{2} k_{\mathrm{B}} T_{0}(1 & \left.+\beta \frac{\Delta V}{V}\right) \times \\
& \times \frac{S}{S+1} \sigma^{2}+\frac{1}{2 \chi}\left(\frac{\Delta V}{V}\right)^{2}
\end{aligned}
$$

where $\chi$ is the compressibility 
Minimizing the energy with respect to the volume variation we obtain directly the volume anomaly corresponding to the equilibrium state at $T<T_{\mathrm{c}}$ :

$$
\frac{\Delta V}{V}=+N \frac{3}{2} k_{\mathrm{B}} T_{0} \beta \chi \frac{S}{S+1} \sigma^{2}
$$

$\Delta V$ is the difference between the volume of the magnetic material and the volume that a non magnetic material (with a similar crystallographic structure) would have (at the same temperature $T<T_{\mathrm{c}}$ ).

We have

$$
\begin{aligned}
\frac{\Delta V}{V}= & -N \frac{3}{2} k_{\mathrm{B}} \frac{\mathrm{d} T_{\mathrm{c}}}{\mathrm{d} P} \frac{S}{S+1} \sigma^{2} \\
& \left(\text { since } \frac{\mathrm{d} T_{\mathrm{c}}}{\mathrm{d} P}=\beta T_{0} \frac{\mathrm{d}(\Delta V / V)}{\mathrm{d} P}=-T_{0} \beta \chi\right) .
\end{aligned}
$$

For a ferrimagnetic material with 2 sublattices, $a$ and $d$, and with only one kind of magnetic ions, and assuming antiferromagnetic interaction between the two sublattices to be dominant, the magnetic energy is [5] :

$$
-N \frac{3}{2} k_{\mathrm{B}} T_{\mathrm{c}} \frac{S}{S+1} 2 \lambda \sigma_{a} \sigma_{d}
$$

where $\sigma_{a}$ and $\sigma_{d}$ are the reduced magnetizations of the two sublattices $a$ and $d$. $\lambda$ is the fraction of magnetic ions in site $a(\lambda=0.4$ for YIG) hence :

$$
\frac{\Delta V}{V}=-N \frac{3}{2} k_{\mathrm{B}} \frac{\mathrm{d} T_{\mathrm{c}}}{\mathrm{d} P} \frac{S}{S+1} 2 \lambda \sigma_{a} \sigma_{d} .
$$

3. Experimental determination of the volume anomaly in YIG. - The thermal expansion was measured between $77 \mathrm{~K}$ and $1000 \mathrm{~K}$ by using a single-rod type silica dilatometer. The length variation of the samples was detected with a linear variable differential transformer. A precision of $0.025 \times 10^{-3}$ was obtained. Figure 1 shows the thermal expansion measured on YIG.

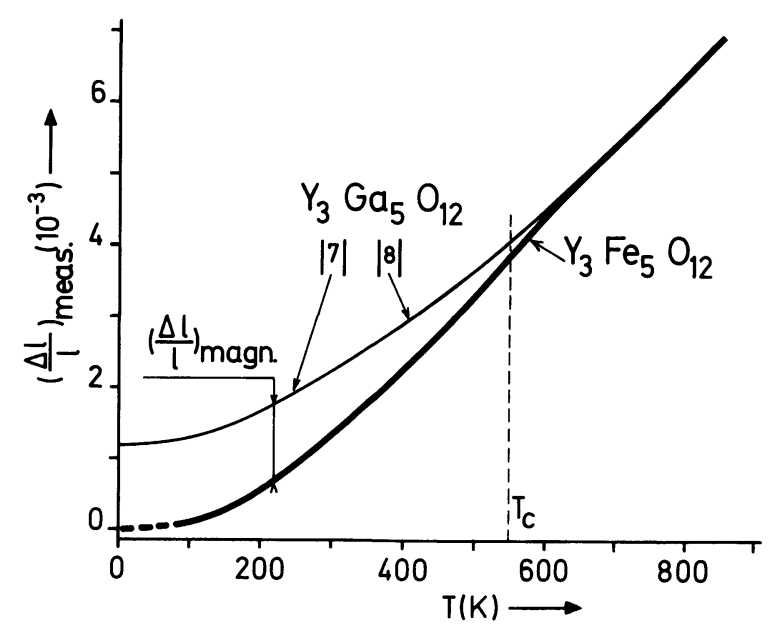

Fig. 1. - Thermal expansion for $\mathrm{Y}_{3} \mathrm{Fe}_{5} \mathrm{O}_{12}$ and $\mathrm{Y}_{3} \mathrm{Ga}_{5} \mathrm{O}_{12}$ versus temperature.
In order to separate the magnetic thermal expansion contribution from that due to the lattice vibrations, we compare the $\mathrm{Y}_{3} \mathrm{Fe}_{5} \mathrm{O}_{12}$ thermal expansion curve with that of the non magnetic garnet $\mathrm{Y}_{3} \mathrm{Ga}_{5} \mathrm{O}_{12}$, whose thermal expansion coefficient, when far from $T_{\mathrm{c}}$ (in the ranges $0-100 \mathrm{~K}$ [7] and 650-1 $000 \mathrm{~K}$ [8]), is the same as the one of $\mathrm{Y}_{3} \mathrm{Fe}_{5} \mathrm{O}_{12}$ in these temperature ranges.

Then, one can separate at any temperature $T \lesssim T_{\mathrm{c}}$ the magnetic contribution from that due to the lattice vibrations :

$$
\left(\frac{\Delta l}{l}\right)_{\text {magn. }}=\left(\frac{\Delta l}{l}\right)_{\mathrm{YIG}}-\left(\frac{\Delta l}{l}\right)_{\text {non magn. garnet }} .
$$

Figure 2 shows the magnetic thermal expansion contribution $(\Delta l / l)_{\text {magn. }}$ of YIG versus temperature. One can see that at $T_{c}$ a deformation is measured, which is due to the short-range order effects (or spin correlation effects).

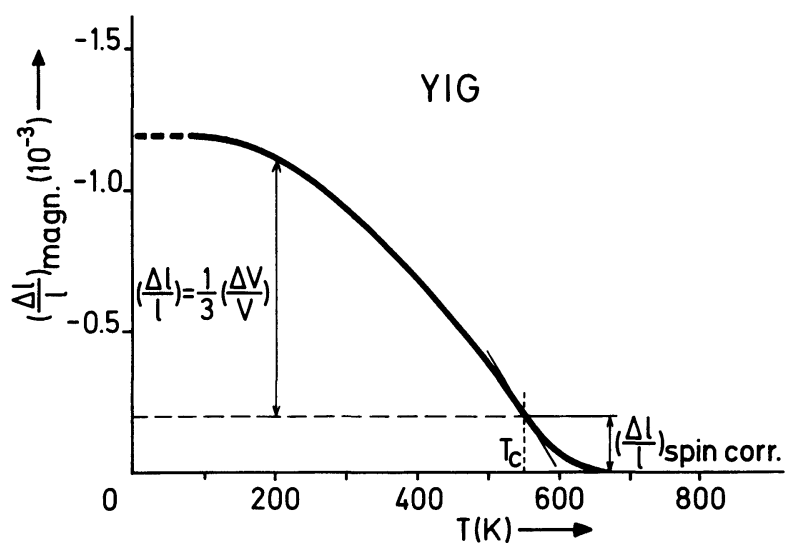

Fig. 2. - Magnetic thermal expansion for $\mathrm{Y}_{3} \mathrm{Fe}_{5} \mathrm{O}_{12}$ versus temperature.

We assume here that, for the analysis of the magnetic thermal expansion contribution $(\Delta l / l)_{\text {magn. }}$, one can separate the ferrimagnetic contribution $(\Delta l / l)$ due to the ferrimagnetic order energy $((\Delta l / l) \neq 0$ for $T<T_{\mathrm{c}}$ and $(\Delta l / l)=0$ for $\left.T \geqslant T_{\mathrm{c}}\right)$ and the shortrange order contribution $(\Delta l / l)_{\text {spin corr. }}$ taking as a first approximation

$$
\left(\frac{\Delta l}{l}\right)=\left(\frac{\Delta l}{l}\right)_{\text {magn. }}-\left(\frac{\Delta l}{l}\right)_{\text {spin corr. }}
$$

with $(\Delta l / l)_{\text {spin corr. }}=(\Delta l / l)_{T_{\mathrm{c}}}$.

This hypothesis seems justified, since we analyse only the length anomaly corresponding to the ferrimagnetic order energy, below $T_{\mathrm{c}}$. This method is comparable with that used to obtain the value of the spontaneous magnetization deduced from a difference between the total saturation magnetization and the magnetization part due to the paramagnetism (this value of spontaneous magnetization is also zero at $\left.T_{\mathrm{c}}\right)$.

Moreover, we find that the YIG thermal expansion 
curves for polycrystals and for single crystals (in the [111] direction) are the same (within the limit of experimental precision $\pm 0.025 \times 10^{-3}$ ). Thus, the volume anomaly is defined as

$$
\frac{\Delta V}{V}=3 \frac{\Delta l}{l}
$$

Then, we find the experimental volume anomaly at $0 \mathrm{~K}$ for YIG :

$$
\left(\frac{\Delta V}{V}\right)_{0 \text { exp. }} \simeq-3.00 \times 10^{-3} .
$$

We can compare this value with that obtained from the theoretical expression (7) using the variation of $T_{\mathrm{c}}$ with the pressure $\mathrm{d} T_{\mathrm{c}} / \mathrm{d} P[15]$ :

$$
\left(\frac{\Delta V}{V}\right)_{0 \text { calc. }} \simeq-2.95 \times 10^{-3} \quad(\text { table } \mathrm{I}) .
$$

Both values agree in magnitude and sign.

Table I. - Comparison of the calculated volume anomaly at $0 \mathrm{~K}(\Delta V / V)_{0 \text { calc. }}$ obtained from the theoretical expression (deduced from the molecular field theory) using the variation of $T_{\mathrm{c}}$ with the pressure $d T_{\mathrm{c}} / \mathrm{d} P$ with the experimental volume anomaly at $0 \mathrm{~K}(\Delta V / V)_{0 \text { exp. }}$ obtained after subtraction of the deformation at $T_{\mathrm{c}}$.

\begin{tabular}{|l|c|c|c|c|c|}
\hline & $\begin{array}{c}N \\
10^{22} \mathrm{~cm}^{-3}\end{array}$ & $S$ & $\begin{array}{c}\left(\frac{\mathrm{d} T_{\mathrm{c}}}{\mathrm{d} P}\right) \\
10^{-9}\end{array}$ & $\left(\frac{\Delta V}{V}\right)_{0 \text { calc. }}$ & $\left(\frac{\Delta V}{V}\right)_{0 \text { exp. }}$ \\
& $\mathrm{K} . \mathrm{dynes}^{-1} \cdot \mathrm{cm}^{2}$ & $10^{-3}$ & $10^{-3}$ \\
\hline $\mathrm{YIG}$ & 2.10 & $5 / 2$ & $+1.20[15]$ & -2.95 & -3.00 \\
\hline $\mathrm{EuO}$ & 2.94 & $7 / 2$ & $+0.37[13]$ & -1.75 & $-1.65[11]$ \\
\hline $\mathrm{MnO}$ & 4.60 & $5 / 2$ & $+0.30[14]$ & -2.05 & $-2.25[12]$ \\
\hline
\end{tabular}

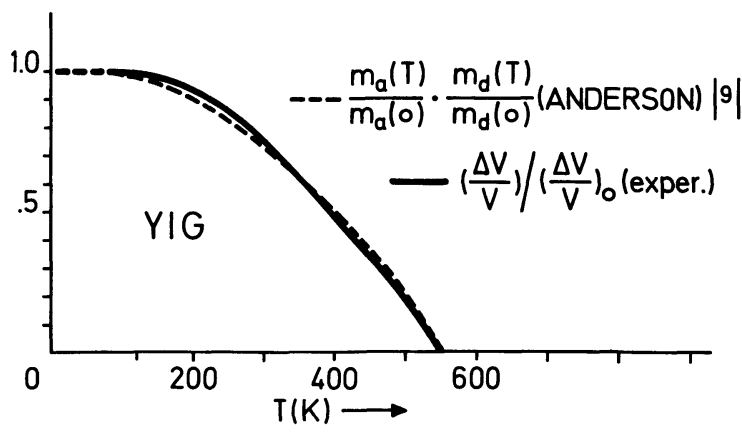

Fig. 3. - Comparison of the volume anomaly temperature dependence with that of the product of the sublattice reduced magnetizations, for $\mathrm{Y}_{3} \mathrm{Fe}_{5} \mathrm{O}_{12}$.
Figure 3 shows the experimental variation of $\frac{\Delta V}{V}(T)$ as a function of temperature for YIG. This temperature dependence is compared with the product $\sigma_{a}(T) \sigma_{d}(T)$ of the temperature dependences of the reduced magnetizations of the 2 sublattices $a$ and $d$ found by Anderson [9] on the basis of Néel's theory of ferrimagnetism : the temperature dependences are in good agreement.

4. Comparison with other materials : insulating ferromagnetic, antiferromagnetic. - Using the same method to obtain the volume anomaly corresponding to the exchange energy associated with the magnetic order state below $T_{\mathrm{c}}$, we deduced the quantity $\Delta V / V$ from the experimental curves published for europium oxide $\mathrm{EuO}$ [11] (insulating ferromagnetic) and for manganese oxide $\mathrm{MnO}$ [12] (antiferromagnetic). When comparing these experimental curves with those corresponding to the thermal expansions of the lattice vibrations deduced from a Debye-type law [11, 12], and subtracting the deformation at $T_{\mathrm{c}}$ we find :

$$
\begin{aligned}
& \left(\frac{\Delta V}{V}\right)_{0 \text { exp. }} \simeq-1.65 \times 10^{-3} \text { for } \mathrm{EuO} \\
& \left(\frac{\Delta V}{V}\right)_{0 \text { exp. }} \simeq-2.25 \times 10^{-3} \text { for } \mathrm{MnO} .
\end{aligned}
$$

These experimental results were also compared with those obtained from the theoretical expression (5) which gives the volume anomaly as a function of the variation of $T_{\mathrm{c}}$ with the pressure $\mathrm{d} T_{\mathrm{c}} / \mathrm{d} P$ (table I).

The results are in good agreement.

Moreover, when plotting $(\Delta V / V)_{\text {exp. }} /(\Delta V / V)_{0 \text { calc. }}$ versus $T / T_{\mathrm{c}}$ (Fig. 4) we obtain a reduced temperaturedependence curve for all the three magnetic structures (ferri-, antiferro- and ferromagnetic) with localized moments.

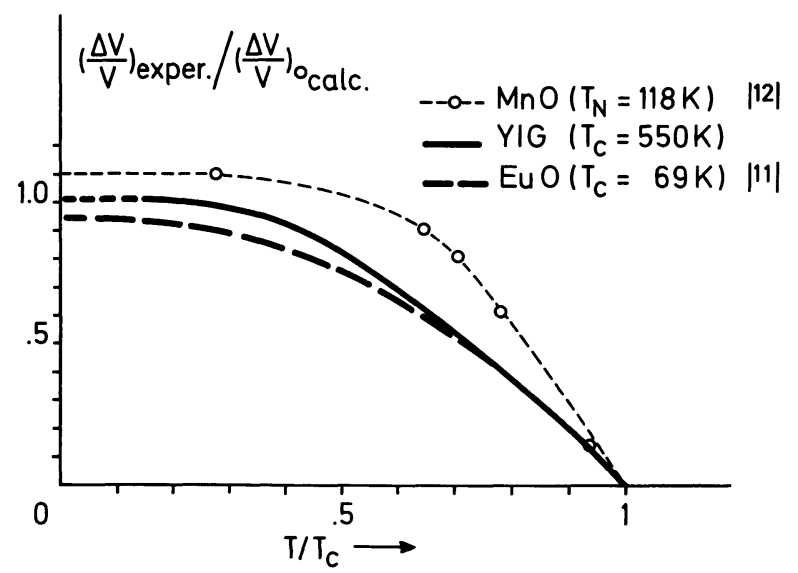

Fig. 4. - Reduced curves of volume anomaly versus temperature for ferrimagnetic, antiferromagnetic and ferromagnetic materials with localized magnetic moments. 


\section{References}

[1] Globus, A., J. Physique Colloq. 38 (1977) C1-1.

[2] NéEl, L., Ann. Phys. 8 (1937) 237.

[3] Bloch, D., J. Phys. Chem. Solids 27 (1966) 881.

[4] Bloch, D. and Georges, R., Phys. Rev. Lett. 20 (1968) 1240.

[5] SMaRT, J. S., Effective field theories of magnetism (W. B. Saunders Cy) 1966, p. 29 and p. 125.

[6] Bean, C. P. and Rodbell, D. S., Phys. Rev. 126 (1962) 104.

[7] Sayetat, F., Thèse, Grenoble (1974) p. 209.

[8] Geller, S., Espinosa, G. P., Fullmer, L. D. and Crandall, P. B., Mat. Res. Bull. 7 (1972) 1219.

[9] Anderson, E., Phys. Rev. 134 (1964) A 1581.
[10] NÉEL, L., Ann. Phys. 3 (1948) 137.

[11] Argyle, B. E., Miyata, N., Phys. Rev. 171 (1968) 555

[12] Bloch, D., Charbit, P., Ggorges, R., C. R. Hebd. Séan Acad. Sci. B266 (1968) 430.

[13] McWhan, D. B., Souers, P. C. and Jura, G., Phys. Rev. 143 (1966) 385.

[14] Bartholin, H., Bloch, D. and Georges, R., C. R. Hebd. Séan Acad. Sci. B264 (1967) 360.

[15] Bloch, D. and Pavlovic, A. S., Adv. High Pressure Res. 3 (1969) 71. 